\title{
A polyocular framework for research on multifunctional farming and rural development
}

\author{
Egon Noe \\ Danish Institute of Agricultural Sciences, Department of Agroecology and Environment, \\ P.O. Box 50, DK-8830 Tjele, Tel: + 458999 1207, Fax: + 4589991200 \\ E-mail: Egon.Noe@agrsci.dk \\ Hugo Fjelsted Alrøe \\ Danish Research Centre for Organic Food \&Farming (DARCOF) \\ http://alroe.dk/hugo \\ Anne Mette S. Langvad \\ Regional Development, Central Denmark Region, Skottenborg 26, 8800 Viborg \\ E-mail: AM.Langvad@ru.rm.dk
}

\begin{abstract}
The paradox of multifunctionality is that, on the one hand, the specialized functionalities of agriculture only arise because of the functional differentiation of social systems and scientific disciplines and, on the other hand, multifunctionality can only enter as a way to mediate between conflicts, interests and fragmented knowledge when different functions and observations of functions combine. The aim of this paper is to contribute to a theoretical and methodological platform for multidisciplinary research on multifunctional farming. With the notions of polyocular cognition and polyocular communication we introduce a second order, interdisciplinary communication process that can meet the challenge of creating a shared view on multifunctional farming. Polyocular communication must be based on other rules than the rules of the involved disciplines. Whereas disciplinary communication is about providing consistent, efficient and precise knowledge in the context of a sharply delimited research world, polyocular communication is about extending a multidimensional space of understanding.
\end{abstract}




\section{Introduction}

The aim of this paper is to contribute to a theoretical and methodological platform for multidisciplinary research on multifunctional farming. This aim is rooted in a widely shared understanding that future sustainable development of agriculture not only is a matter of development of multi-functional solutions offered by the different perspectives involved in sustainable development, but also a matter of involving multidisciplinary knowledge (Huylenbroeck and Durand 2003). This understanding is also expressed in the many national and European calls for cross- and multidisciplinary projects (e.g. MEA-Scope, Multagri).

On the face of it, both the notions of multifunctionality and multidisciplinarity seem obvious and easy to apply. However, our experiences from involvement in multidisciplinary teams and from working with the subject of multifunctionality indicate that, first of all, it is very difficult to obtain a common understanding of the research object in multidisciplinary research, and, on top of that, it is very difficult to obtain a common understanding of the notion of multifunctionality.

This paper builds on three fundamental insights gained from these experiences:

1) Multifunctionality inherently involves a plurality of perspectives. No single discipline can fully incorporate all these different perspectives, and therefore research on multifunctional agriculture has to be multidisciplinary.

2) Multidisciplinarity, in itself, is not trivial. The challenges and problems of multidisciplinarity are deeply rooted in the differentiation into disciplines that operate in different codes, delimitations, times and scales. The differentiation destroys the options for bringing the observations together on the same formula, and multidisciplinary research therefore needs a framework for handling different disciplinary perspectives.

3) The problems with operationalizing the notion of multifunctionality are rooted in the same substantial and fundamental philosophical problematic of communication and cooperation in multidisciplinary teams, but with the added complexity that the perspectives of disciplines here meet the perspectives that are already inherent in the research object, multifunctional farming. The result is that different disciplines operate with different definitions and delimitations of multifunctionality, and this makes it even more difficult to communicate on multifunctional farming.

In this paper we try to understand why multidisciplinary research on multifunctional farming is such a difficult task, outline a semiotic theoretical basis for this understanding and present what we have labelled a polyocular framework for multidisciplinary research on multifunctional farming. Before we turn to the theoretical understanding and the related framework, we will go deeper into some reflections on the notion of multifunctionality.

\section{The notion of multifunctionality}

From a contemporary perspective, all farms were multifunctional in their way of organising a century ago. Not for ideological reasons or because of certain values, but because of the purposefulness of multidimensionality. At the time, the majority of 
people were farmers and the farm was the limit of their mental universe. Therefore multifunctionality was simply a non-conceptualized way of agricultural practice.

Agriculture, like the rest of society, has undergone a functional differentiation into subsystems that operate from specialised, function-specific perspectives as a means to increased efficiency (Kneer and Nassehi 1997: 136). In the European context these differentiation and specialisation processes have been strongly supported by post war policies (Moreira 2004).

One may claim that the differentiation processes have been very successful in terms of efficiently pursuing the goals of the differentiated perspectives, since the functional differentiation of society has achieved an enormous intensification (Luhmann 1995: 476). In recent decades we have seen an even stronger specialisation into oligofunctional farms, the major rationale and driving forces now being the changing production conditions in terms of technological and organizational developments and the globalisation of markets. Agricultural specialisation has led to such a tremendous increase in productivity that, until the seventies, it was commonly perceived as a success story (although there were rising critiques in the sixties). After that, the political importance of productivity gradually decreased, and other farm produced benefits gained focus and became demanded by society.

The seventies raised a debate mainly focusing on the environmental aspects of modern, industrialised agriculture. From then on, the many unintended (and unseen from the dominant perspectives) side effects of farming on the environment, landscapes and the options for livelihood in rural areas led to a focus on the viability of smaller farms, employment in connection with local diversified production and rural social life on a whole, and with the Brundtland report in 1987 this crises of agricultural development was generally framed as a sustainability debate.

In the nineties, the notion of "multifunctionality" gained increasing importance as a way to operationalize sustainable development, a way to reintroduce a range of different perspectives into the development of agriculture, both the pre-productivity perspectives and the new perspectives introduced by the sustainability discourse (Wilson 2007).

Farm based rural development covers many aspects related to the farm character and its contribution to the local area (Marsden 2003). From a farming perspective, this may be farm activities that result in more value added per unit of product, diversification of activities to include new non-agricultural activities such as agro-tourism, nature and landscape management, and household resource mobilization through e.g. farming economically or off-farm incomes (Ploeg and Renting, 2004). The potential of farm based rural development for raising the income level on farms as well as in the wider rural economy has been demonstrated (Ploeg and Renting 2000 and 2004, Gorman et al. 2001, Ventura and Milone 2000, Roest and Menghi, 2000, Knickel 2001, Knickel et. al 2004, Mielgo et al. 2001).

It is in the above context that the term of multifunctionality gains meaning as a tool for focusing not only on the negative side effects of farming, which are emphasized in the sustainability debate, but also on the positive effects that we want farming to have for the rural areas (OECD, 2001). 
Although policies such as the CAP and GAP have contributed to the development into specialised and more effective oligo-perspectives, our claim is that the crisis of agriculture is not only rooted in failed policies, but in the much deeper co-development of various differentiation processes within science, market, technology, etc. (Norgaard 1994). Policy is important, but if the problem is seen only as a policy problem, we will fail to address the real underlying processes. This paper deals with how we, within science, can handle such fundamental social processes of differentiation of perspectives.

\section{The problems and challenges of the plurality of perspectives}

Various approaches have been developed to deal with the reintegration of perspectives, such as systems theory, modelling, learning theory and cross-disciplinary research in various forms. Often the search for a comprehensive approach has led to an unfruitful opposition between "reductionist" and "holistic" science. From the holist point of view, reductive methods are bad science because they do not capture the connectedness of complex reality, and from the reductionist point of view, reductive methods ensure the quality of science and other methods are, therefore, not scientific (Alrøe and Kristensen 2002).

Our claim is that none of these "reintegration" approaches have really managed to solve the basic problems of the nature of functional differentiation into function-specific perspectives. Either they are ignoring the fundamental problems of reintegration of perspectives or they are just introducing a new (so-called holistic) perspective that neglects the others.

Some of these problems may best be illustrated by cases based on projects that we have been involved in.

The first case is a multidisciplinary research project on nature quality in relation with organic farming ${ }^{1}$. Four disciplines, and thereby four perspectives, were involved: one focusing on soil fauna, one focusing on the flora of small biotopes, a geographical perspective on landscape and a sociological perspective on farmers' and farm families' perception of landscape and nature values. From a first glance it looks like a perfect multidisciplinary project and the involved researchers were all keen on working together. In the project, a series of cross-cuttings were organised to improve the multidisciplinary outcome of the project. We also agreed on working on the same locations (study areas). Twice a year, a two-day workshop was organised, and part of this workshop was a visit of one of the study areas. Although it was a very interesting project, generating a lot of insight, it, in our opinion, never succeeded in reintegrating the insights from the individual disciplines in a multidisciplinary understanding, apart from the fact that the individual disciplines were challenged and stimulated by these multidisciplinary experiences. In our analysis there were at least two main barriers to a deeper integration in this project. One: we were not observing the same object. To agree on a shared study area is not the same as to agree on the same object. In the project there was no shared platform that interlinked the different objects studied from the different perspectives: the micro organism in the soil, biodiversity in the small biotopes, the management of the farm and the social dimension of organic farming. Two: the objects were not observed from the same understanding of nature quality, each approach operated so to speak from its own more or less explicitly embedded theoretical and 
philosophical understanding of nature quality, which made the communication across perspectives very complicated (Tybirk et al. 2004; Hansen et al 2006; Noe et al 2005).

We do not think this was a trivial problem caused by especially stubborn researchers; on the contrary, most researchers showed a cooperative spirit right from the beginning. It was a more fundamental problem linked with the core nature of disciplinary differentiation into different perspectives, which implies a perspective-based definition and demarcation of the object.

The second case that we draw on here is a large EU-project on multifunctional farming, MEA-Scope ${ }^{2}$. In our view, this case illustrates the classical solutions to the above problems of reintegrating perspectives.

In MEA-Scope, mainly three different disciplines were involved, agronomy, economics and sociology, each with their own approach to multifunctionality. The project aim was: "to develop an integrated framework for the assessment of the multifunctionality impacts of CAP reform options”. The key rationale of the project was to integrate three different modelling tools, an agronomical tool at the farm level, a farm based economical tool and a region based economical tool, which in combination could simulate the effect on different policy measures.

The project was born with two good intentions in terms of an integrated framework: the first was to have an open discussion of the concept of multifunctionality, the second was to involve a sociological perspective in the exploration of the local perspectives of the case study areas. Again, case study areas were selected as a platform for cooperation and integration of the different perspectives involved.

At the end of the day, the concern for the interplay between the three modelling tools meant that economy got a hegemonic position with regard to both the definition and operationalization of the notion of multifunctionality and the questionnaire by way of which the demand of multifunctionality was explored in the case study areas. Only observations that could be translated into the language of economical modelling were regarded as observations in the project. We think this is similar to what is happening in many projects involving more perspectives and disciplines: the integration is based on the hegemony of one discipline. It is not a question of more or less sympathetic approaches; a hegemonic position of one perspective is always a violation of the other perspectives.

To sum up, a framework for dealing with multifunctionality in a multidisciplinary way must relate to the following core problematic:

- Multifunctional agriculture cannot be meaningfully reduced to a single perspective.

- Multifunctionality constitutes a disciplinary challenge with respect to its definition and the methodology for research in multifunctionality.

- Difficulties with communication arise from these facts, though they may not be insurmountable.

From a semiotic standpoint, we construct a polyocular framework to interrelate the various disciplinary perspectives. The theoretical construction leads to a methodological outline of how multidisciplinary observations of multifunctionality can be taken into 
practise, and how, at the same time, multifunctional agriculture can retain its dynamical character.

\section{A polyocular framework for multidisciplinary studies of multifunctionality}

The theoretical framework that we present in the following, is primarily inspired by Peircean semiotics, Luhmannian systems theory and the tradition of Actor-NetworkTheory (ANT).

\section{A semiotic understanding of functions}

Multifunctionality implicates the existence of multiple functions, but the question is how these functions come about. An objectivist position on this matter would point to the internal characteristics of the object, potentially giving rise to its functions. This point of view is widespread within e.g. the landscape ecology tradition (Brandt and Vejre 2003, 2004), but it furthers a mechanistic understanding of the properties of objects as determining for functions in and by themselves.

But function, as a concept, is about action with an implicit purpose, it implies concepts such as agency, effect, performance and achievement. Thereby, a hermeneutic perspective on the character of functions is introduced. Within such a frame of reference, functions do not exist only with reference to the object; they are always in need of an observer or an interpretation that provides the meaningful perspective by way of which a function can be deemed as functioning. This hermeneutic aspect of functions can be analysed in a terms of a Peircean semiotic framework. According to Peirce:

"A sign is something which stands to somebody for something in some respect or capacity.” (Peirce, 1897, CP: 2.228)

“... it is necessary to distinguish the Immediate Object, or the Object as the Sign represents it, from the Dynamical Object, or really efficient but not immediately present object.” (Peirce, 1908, CP: 8.343)

The semiotic relation between the really efficient dynamical object and the immediate object, that represents the dynamical object is graphically illustrated below (Figure 1).

An example that illustrates the elements of signification and the semiotic relation between the immediate and the dynamical object could be the sign "dairy cow". "Dairy cow" is the description (representamen, in Peircean terms) of the immediate object of a cow with respect to its "ability to produce milk." The immediate object has its ultimate reference point in the dynamical object of a cow as an "animal with a surplus of possible functions" such as meat, skin colour and ability to eat grass - reference points that could be the immediate objects of other signs that refer to the cow as a dynamical object. Finally, the interpretation of the sign could be "a cow producing milk for an income”.

If we take another example of signification in relation to a cow as dynamical object, the description "grazing cattle" would represent the immediate object of a cow with respect to its quality of "living from eating grass and other vegetation", again with an ultimate reference point in the dynamical object of a cow, and the interpretation of the sign could be "an animal that conserves meadows and fringes by keeping them free of seedlings and high vegetation”. 
[Insert about here: Figure 1]

According to Peirce, three analytically distinctive operations are performed within the signification process. One is the selection of an immediate object from the redundancy of possibilities pertaining to the dynamical object, the other is the assigning of a description, and the third assigning a logic linking the quality of the immediate object with its function or use, the interpretation. Peirce uses the notion of habits of signs that assign a shared linguistic meaning.

It is important to stress that, in Peirce's sense, there is no position from where we can observe the dynamical object as such; every perspective only adds to the number of immediate objects that refer to the dynamical object. This semiotic understanding thereby also becomes the foundation of Peirce's theory of science.

Based on the above examples, a function can be determined as a semiotic relationship that comprises an immediate object and an interpretation with reference to a dynamical object (figure 2). Referring again to the first example above, "dairy cow” is a description of one of the functions of a cow. The ascription and existence of functionality necessarily involves a signification process, and the Peircean semiotic offers a theory and a terminology for a deeper analysis of functionality.

The hybrid semiotic and interactive relations of multifunctionality

Above, we have developed an understanding of function as a semiotic relationship. Before we can elaborate on an empirical framework dealing with multifunctional agriculture as a dynamical object, we need to go one step further in developing this semiotic understanding of functions.

The Peircean notion of the dynamical object may also be understood as a conception of the object en soi prior to any observation or labelling. ${ }^{3}$ Even though signs belong to observers in some sense, they are dependent on the potentiality of the dynamical objects; the objects may strike back so to speak, they may determine the sign in certain respects. Recognizing functions as semiotic is a big and necessary step toward understanding multifunctionality, but it also presents us with a new problem; the problem of better understanding the relation between signs and immediate objects on the one side and dynamical objects on the other. The relation between a function and its dynamical object is not only a semiotic reference to an object "en soi", but also an interactive relation.

[Insert about here: Figure 2]

In search for a theoretical platform to help us understand the hybrid semiotic and interactive relations of multifunctionality, we turn to the heirs of semiotics in ActorNetwork-Theory (ANT).

ANT unfolds to us the dynamics of l'être pour soi, that is the "relatively independent" reality of immediate objects as real abstractions, and by doing so they point to the co-evolution of dynamical objects with immediate objects.

Digging deeper into the exact lines of dynamic interrelations between the dynamic and immediate objects requires a short introduction to ANT notions of actor and network. 
"An 'actor' in ANT is a semiotic definition - an actant - that is, something that acts or to which activity is granted by others.” (Latour, 1997:6)

In accordance with this definition we will use the term "actant" for the actors of ANT. The notion of an actant is not linked to the quality of the entity as such, but to the quality of the entity in the frame of the network into which the entity is mobilised:

" ...For the semiotic approach tells us that entities achieve their form as a consequence of the relations in which they are located. But this means that it also tells us that they are performed in, by, and through those relations.” (Law, 1999:4)

When Peirce is translated into ANT terminology, the immediate object is equivalent to the actant within actor-networks. The sign is equivalent to the network, that is, the context in which the dynamical object is actualised in some respect or capacity to the network. Like the immediate object only exists within the triadic sign in the presence of an interpretant, the actants are performed within actor networks, only.

"[Actor-networks] are neither objective nor social, nor are they effects of discourse even though they are real, and collective, and discursive ...... the networks are simultaneously real, like nature, narrated, like discourse and collective, like society.” (Latour 1993:6)

In ANT there is no hierarchy of interaction. Heterogeneous actors in actor-networks like knowledge, machines, livestock and chemical products are all at the same level of interaction in the network; each element is able to influence strongly the interpretation of another and each element links to other elements accordingly. Therefore, within the network, there is no subject-object hierarchy, just internal functionality. This is exactly why new reality potentially arises from these networks and the above citation becomes exact.

ANT helps us to grasp the evolutionary dynamic interaction between the dynamical object and the immediate object, which as a co-evolutionary process contributes to the potentiality of the dynamical object; in other words, the fact that our interactions with the world influence the potentiality of the world. New dynamical objects or new aspects of the dynamical objects are continually generated by way of the interplay between dynamic and immediate objects - and as a consequence reality evolves and augments.

From a Luhmannian point of view new objects can only be generated by way of selection of possibilities. Noe and Alrøe (2003, 2005a, 2005b) have described the autopoiesis of actor-networks trough selection by the example of a farm enterprise: Seen from an autopoietic point of view, food-production may be organised in numerous ways according to different goals and purposes. The farm enterprise as a heterogeneous social system is not only forced to select in the contingency of the potential dynamical objects that can be mobilised into the farming processes as immediate objects, but also in the contingency of the potentiality related to each dynamical object behind the immediate object, that is enrolled; e.g. a computer can be enrolled as devise for the yearly accounting or as part of a daily steering system.

It leads to the understanding that multifunctionality arises only as a consequence of the differentiation of perspectives; it exists due to the unfolding of different actornetworks. Each perspective attaches different values, understandings and interests to the 
dynamical object. In terms of functionality and potential reality there is a lot of difference as to whether a landscape is seen in light of agricultural production, ecosystem services, environmental protection, game hunting, rural development or aesthetical experiences.

In the following part we explain why communication of a certain type is needed for a successful multidisciplinary study of multifunctionality.

\section{The paradox of multifunctionality}

As previously explicated a function is a semiotic relation where an immediate object is selected by an observer - or, in ANT terminology, a relation where a dynamical object is actualised as an actant in an actor-network. Functionalities of course can be shared by a broader collective of observers, provided that they perform similar selections with respect to the dynamical object. However, in a differentiated society there are overwhelmingly many ways in which to generate and attach meaning. The sharing of a description does not secure the sharing of immediate objects in the interpretations of different observers.

In a Luhmannian perspective, each scientific discipline operates as a specialised function system and Luhmann points to the fact that functional, action-oriented perception or precognition is a precondition to specialized disciplinary knowledge. Each discipline has its own perspective. In analogy with broader functional differentiations in society (see Luhmann 1995), disciplinary differentiation processes take place where the disciplinary networks and perspectives are differentiated into new and more specialised disciplines, and in concurrence their institutionalisations undergo symmetrical differentiation processes.

By generating a habit for seeing yield in the perspective of food production, commodity in the perspective of the market and social interactions in the perspective of culture and society, the disciplines pre-cognise certain functions. It is exactly because of this precognition, that it is possible to further differentiate between various forms of yields, commodities or relationships. To perceive by the ascription of a function simply releases the amounts of mental capacity pre-requisite to the performance of deeply specialised science (Luhmann 1995).

As a negative but logically following by-product of disciplinary, functional differentiation, the disciplines generate blind spots as to the values and interests attached to objects by other disciplines. These values and interests are considered largely irrelevant as long as they are not translated into the logic of the specific discipline in question. In other words, the way that agronomy relates to biology is by posing the question of how biodiversity would be of influence to the yield-food production relationship. Another unintended consequence of the differentiated 'immediate objects' being used as representations of 'dynamical objects' in different disciplines, is that communication becomes troublesome, if not directly improbable.

In conclusion, we are confronted with the following paradoxical fact: Highly specialized functionalities of agriculture only arise because of functional interpretations and functionally motivated observations performed by distinctly differentiated disciplines. At the same time multifunctionality as a way to mediate between conflicts and interests, can only be a fact when different functions and observations of functions combine. Furthermore there is no way back to an undifferentiated world and science; differentiation is an irreversible process. The only way leads forward. 
To loosen up this apparent Gordian knot, we need to turn to a qualitatively different type of cognition. We do that by introducing the Japanese theoretician, Magoroh Maruyama.

As well as Peirce and Luhmann, Maruyama is engaged in the problem of cognition, but in contrast to the former authors he focuses upon perceptive depths. Considering Bateson's binocular vision, which makes use of the differences between the two images to enable the brain to compute the depth, which is invisible to both eyes, Maruyama invents the concept of polyocularity. In polyocular vision, the differences between several images enable us to compute invisible dimensions, which cannot be obtained by adding several images (Maruyama 1978, 1985, 1995, 2004). In Bateson's (1979) terms, the information brought by depth is of a different logical type than the information gained from the two images, separately. We can expect to find such invisible dimensions, whenever we compare different images, in line with Bateson's definition of information as "difference that makes a difference", i.e. a cognized difference at a different logical level. Thus, according to Maruyama's concepts, the differences between plural oculars are what render the most comprehensive and meaningful understanding of an object.

Translating Luhmann's theory of disciplinary differentiation into Maruyama's vocabulary, we could say that, in contrast to individual cognition, disciplinary cognition is mono-ocular, due to the logic of differentiation. Disciplines have a one-dimensional way of recognizing, in order to be able to specialise. Consequentially, if the sciences ${ }^{4}$ are to reach a multifunctional understanding, they have to mobilize their observations as actants in multidisciplinary communication.

Figure 3 may act as a concretization. This figure illustrates how different disciplines observe and ascribe different functions to the same dynamical object. The disciplinary communication is not enlarged or extended to multidisciplinary communication. But the multidisciplinary communication is dependent on the mobilisations of facts and insights produced by the disciplines. Multidisciplinary and disciplinary communications need to be separated, and thereby to be environments to each other, because the two types of communications operate on different logics, interests and values. The figure additionally describes how - as an essential part of multidisciplinary communication - the disciplines are stimulated to reflect upon their own cognition.

Finally, we turn to a discussion of how such multidisciplinary communication can be organised in praxis, by returning to the two cases described in the first part of the paper.

[Insert here: Figure 3]

\section{How can the framework of polyocularity help multidisciplinary work on multifunctionality?}

This paper has shown how the notion of multifunctionality has evolved from the differentiation of perspectives and the consequences of this differentiation process. The differentiation of perspectives improves our ability to pursue the goals of each perspective: increase the yield, reduce the costs, increase the productivity, etc. However, the price to pay for this efficiency is the so-called unintended side effects, which the differentiated perspectives cannot deal with and which violates the sustainability of the 
resulting production systems, and the blindness of the dominating perspectives to new societal demands on agriculture.

In its short history, various approaches have been offered as solutions to the problematic of multifunctionality. There is an agreement in the literature on the necessity of involving many disciplines to cope with the many aspects or perspectives of multifunctional agriculture. The major solution has been to strive for holistic or system orientated approaches that try to cope with all the relevant functions or perspectives at the same time. On the face of it, this seems to be a very promising approach. In practise, however, this approach turns out widely to fail in this reintegration of the different perspectives, and to do even worse because it neglects its own necessary blindness due to its understanding of being systemic or holistic and, hence, 'all-seing'.

In this paper we have identified two key problems of working multidisciplinarily with multifunctionality: how to handle the different objects of different disciplines in multidisciplinary research, and how to integrate the different functions in multifunctionality. We have introduced a theoretical platform with two key notions that we argue can constitute a fruitful pathway for multidisciplinary work on multifunctionality. The first notion is the dynamic object and the other is polyocularity 5 .

Returning to the cases described earlier, how can the theoretical platform and the notions of dynamic object and polyocularity help us to overcome the problems that we have identified?

In the case of the nature quality project, the notion of immediate and dynamic object could help to understand and handle the fundamental problem of multidisciplinary projects that immediate objects belong, so to speak, to perspectives and thereby to the different disciplines. There is no way in which the logic belonging to any one of the perspectives can interlink the immediate objects of the different perspectives. The interlinking of the biological, the geographical and the sociological perspectives on nature quality cannot be made from the inside logic of either of these disciplines. Only as a process of a second order can the links between these different immediate objects be discussed and related to each other without violating the insights that have been generated by the involved perspectives. There is no blueprint as to how this second order process can be performed, but the acknowledgement of the limitation of the first order perspectives is a precondition for any second order communication. These problems of communication were only realised at a very late stage in the research project, and at that time it was too late to do anything substantially about it in relation to the synthesis work in the project. We believe that it is important, very early in such a project, to work on this second order understanding of the dynamic object, which may interlink and connect the first order immediate objects of the involved disciplines. It is very helpful and fruitful to work in the same workshop area, but it is not enough to ensure a second order platform for a shared dynamic object in terms of interrelated immediate objects.

With regard to the second case, the MEA-Scope project, the platform does not offer any easily applicable solution. MEA-Scope is an example of a project where one disciplinary perspective has taken the hegemonic position of being the integrating perspective of multifunctionality. The only way out of this problem is to acknowledge that the economic modelling provides just one perspective on the dynamic object, and to let the output of the modelling be just one of the inputs to a separate polyocular communication process within the project, instead of demanding that the input of the other perspectives must be translated into inputs to the economic modelling. 


\section{Beyond the paradox of multifunctionality}

The paradox of multifunctionality is that, on the one hand, the specialized functionalities of agriculture only arise because of the functional differentiation of social systems and scientific disciplines and, on the other hand, multifunctionality can only enter as a way to mediate between conflicts, interests and fragmented knowledge, when different functions and observations of functions combine.

This paradox is the main cause of why multidisciplinary research on multifunctional farming is such a difficult task, but it is also the source of a new understanding. The way to overcome this paradox is not to go back to a pre-differentiated science, but to move forward to incorporate communication processes of a second order.

The notions of polyocular cognition and polyocular communication offer a theoretical understanding and platform for this second order, interdisciplinary communication - both in relation to the challenge of creating a shared object that we saw in the nature quality case, and to create a polyocular view on the multifunctionality of the dynamic object. These two processes, creating a shared object and creating a polyocular view, are thereby totally dependent, because second order multidisciplinary communication can only be performed with reference to a shared dynamic object, which we agree upon can be perceived in a number of different ways. Furthermore, polyocular communication must be based on other rules than the rules of the involved disciplines. Whereas disciplinary communication is about providing consistent, efficient and precise knowledge in the context of a sharply delimited research world, polyocular communication is about extending a multidimensional space of understanding.

\section{Notes}

1. "Nature Quality in Organic Farming”, a research project under the Danish Research Centre for Organic Farming [http://www.darcof.dk/research/darcofii/iii5.html, http://orgprints.org/view/projects_refereed/da2c5.html].

2. "Micro-economic instruments for impact assessment of multifunctional agriculture to implement the Model of European Agriculture”, a Policy Oriented Research Project of the European Commission Sixth Framework Programme [http://www.mea-scope.org].

3. "En soi" refers to Sartrean philosophy of existence (Sartre 1943).

4. We use "science" in a broad sense, including social sciences and the humanities

5. In a separate paper we have applied these notions in a slightly different manner, using a polyocular approach to different (non-disciplinary) actor perspectives on the dynamic object of organic agriculture (Alrøe and Noe 2008).

\section{References}

Alrøe, H.F. (2000) Science as Systems Learning: Some reflections on the cognitive and communicational aspects of science. Cybernetics \& Human Knowing, 7 (4) pp. $57-78$

Alrøe, H. F. and E. S. Kristensen (2002) Towards a systemic research methodology in agriculture: Rethinking the role of values in science. Agriculture and Human Values 19 (1) pp. 3-23

Alrøe, H.F. and E. Noe, (2008) What makes organic agriculture move - protest, meaning or market? A polyocular approach to the dynamics and governance of organic agriculture. International Journal of Agricultural Resources, Governance and Ecology (forthcoming 2008) 
Bateson, G. (1979) Mind and Nature: A Necessary Unity. (Bantam Books)

Brandt, J. and H. Vejre (ed.) (2003) “Multifunctional Landscapes - Monitoring, Diversity and Management”. Vol. II, (Southampton: WIT Press)

Brandt, J. and H. Vejre (ed.) (2004) "Multifunctional Landscapes - Theory, Values and History”. Vol. I, (Southampton: WIT Press)

Cerf, M., D. Gibbon, B. Hubert, R. Ison, J. Jiggins, M. Paine, J. Proost and N. Röling (Eds.) (2000) Cow up a tree - Knowing and Learning for Change in Agriculture Case studies from Industrialised Countries, (INRA editions Paris)

Gorman, M., J. Mannion, J. Kinsella and P. Bogue (2001) Connecting Environmental management and farm Household livelihoods: The Rural Environment Protection Scheme in Ireland. Journal of Environmental Policy and Planning 3 pp. 137-147

Hansen, L., E. Noe and K. Højring (2006) Nature and nature values in organic agriculture. An analysis of contested concepts and values among different actors in organic farming. Journal of Agricultural and Environmental Ethics 19 (2) pp. 147-168

Huylenbroeck, G.v. and G. Durand (2003) Multifunctional Agriculture - A New Paradim for European Agriculture and Rural Development. ASHGATE, Hampshire.

Kneer, G. and A. Nassehi (1997) Niklas Luhmann - introduktion til teorien om sociale systemer. Hans Reitzels Forlag, København. [German edition: Niklas Luhmanns Theorie sozialer Systeme. Eine Einführung. Fink-Verlag, München 1993.]

Knickel, K. (2001) The marketing of Rhöngold Milk: An Example of the Reconfiguration of Natural Relations with Agricultural Production and Consumption. Journal of Environmental Policy and Planning 3 pp. 123-136

Knickel, K., H. Renting and J.D. van der Ploeg (2004) Multifunctionality in European agriculture. In: Brouwer, F. (ed.) Sustaining Agriculture and the Rural Development. Governance, policy and Multifunctionality. Advances in Ecological Economics, pp. 81-103 (Edward Elgar, Cheltenham, UK)

Latour, B. (1993) "We have never been modern". (Harvester Wheatsheaf, London)

Latour, B. (1997) Om aktør - netværksteori. Nogle få afklaringer og mere end nogle få forviklinger. Philosophia 25 (3-4) pp. 47-64. [English version (1996) On ActorNetwork Theory: A few clarifications. Soziale Welt 47 (4) pp. 369-381. Available online at $\quad<$ http://amsterdam.nettime.org/Lists-Archives/nettime-l9801/msg00019.html>]

Law, J. (1999) After ANT: complexity, naming and topology. In Law, J. and Hassard, J. (Eds.), Actor-Network Theory and after. (England. Oxford: Blackwell Publisher)

Luhmann, N. (1995) Social systems. (Stanford University Press)

Marsden, T. (2003) “The Condition of Rural Sustainability” (Waageningen: Royal van Gorcum)

Maruyama, M. (1978) Endogenous Research and Polyocular Anthropology in Perspectives on Ethnicity. Ed. R. Holloman and S. Arutiunov, (The Hague: Mouton Publisher)

Maruyama, M. (1985) Mindscapes: How to understand specific situations in Multicultural Management. Asia pacific journal of Management 2 (3) pp. 125149

Maruyama, M. (1995) Individual Epistemological Heterogeneity across cultures and its use in organisations. Cybernetica, 37 (3) 215-249

Maruyama, M. (2004) Polyocular vision or subunderstanding? Organization Studies 25 pp. $467-480$ 
Moreira M.B. (2004) Globalization: The end of the social contract in agriculture. Manuscript of the keynote speech of the Sixth IFSA European Symposium. Vila Real, Portugal April $4^{\text {th }} 2004$

Mielgo, A.M.A., E.S. Guzmán, M.J. Romera and G.G. Casado (2001) Rural Development and Ecological management of Endogenous resources: The case of Mountain Olive Groves in Los Pedroches comarca (Spain). Journal of Environmental Policy and Planning 3 pp. 163-175

Noe, E. and H.F. Alrøe (2003) Farm enterprises as self-organizing systems: A new transdisciplinary framework for studying farm Enterprises? International Journal of Sociology of Agriculture and Food 11(1) pp. 3-14

Noe, E. and H.F. Alrøe (2005a) Combining Luhmann and Actor-Network Theory to see Farm Enterprises as Self-organizing Systems. Cybernetics and Human Knowing. 13 (1) pp. 34-48

Noe, E. and H.F. Alrøe (2005b) The challenge of management of multidimensional enterprises analysed from a logo-poietic perspective. Working paper http://orgprints.org/3909/

Noe, E., N. Halberg and J. Reddersen (2005) Indicators of biodiversity and conservational wildlife quality on organic farms for use in farm management. Journal of agricultural and environmental Ethics 18 (4) pp. 383-414

Norgaard, R.B. (1994) Development betrayed - the end of progress and a coevolutionary revision of the future. (London and New York, Routledge)

OECD (2001) Multifunctionality Towards an Analytical Framework. [http://pinguet.free.fr/4.pdf]

Peirce C.S. $(1897,1908)$ Charles Sanders Peirce, Collected papers. Edited by Charles Hartshorne and Paul Weiss. (Cambridge: Belknap Press of Harvard University Press, 1958-1966)

Ploeg, J. D.v.d. and H. Renting (2000) Impact and potential: A comparative review of European rural development practices. Sociologia Ruralis 40 (4) pp. 529-543

Ploeg, J. D.v.d. and H. Renting (2004) Behind the "redox": A rejoinder to David Goodman. Sociologia Ruralis 44 (2) pp. 233-242

Roest, K. de and A. Menghi (2000). Reconsidering 'Traditional' Food: The case of Parmigiano Reggiano cheese. Sociologia Ruralis 40 pp. 439-451

Sartre, J.P. (1943) L'Être et le Néant. Paris: Gallimaud.

Tybirk, K., H.F. Alrøe and P. Frederiksen (2004) Nature quality in organic farming: A conceptual analysis of considerations and criteria in a European context. Journal of Agricultural and Environmental Ethics 17 (3) pp. 249-274.

Ventura, F. and P. Milone (2000) Theory and practice of multi-product farms: farm butcheries in Umbria. Sociologia Ruralis 40 pp. 452-465

Wilson G.A. (7007) Multifunctional Agriculture - A Transistion Theory Perspective. CABI, Oxfordshire. 


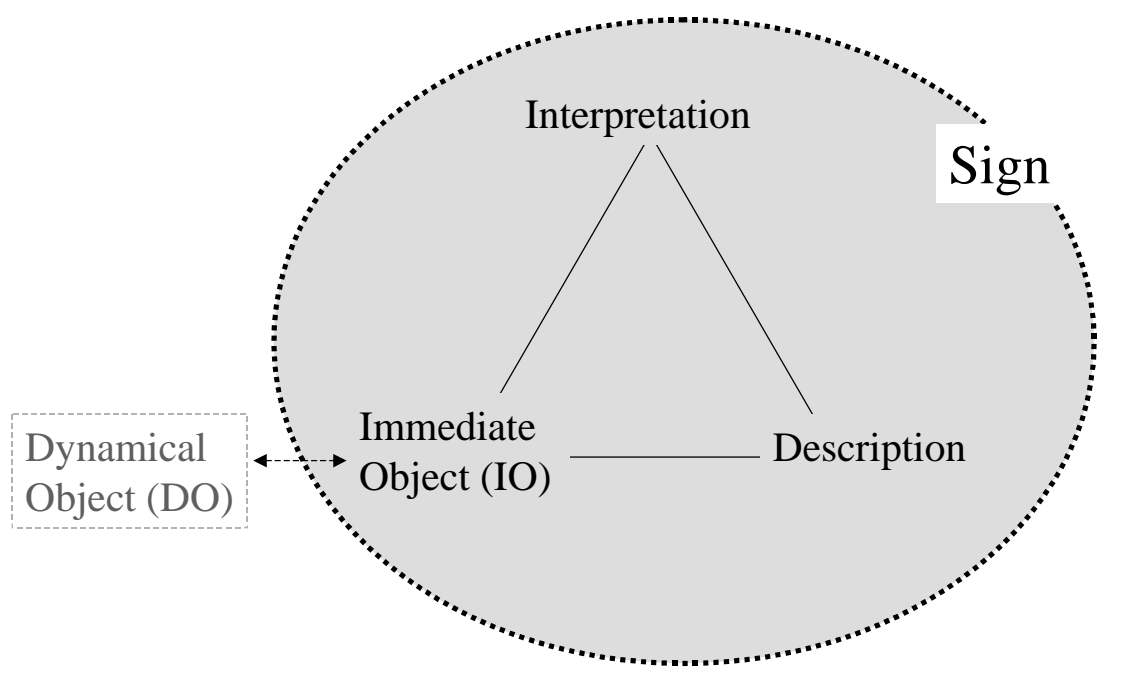

Figure 1: The relationship between the 'dynamical object' and the three elements of the sign, immediate object, interpretation (interpretant), and description (representamen), based on Peirce's semiotic. 


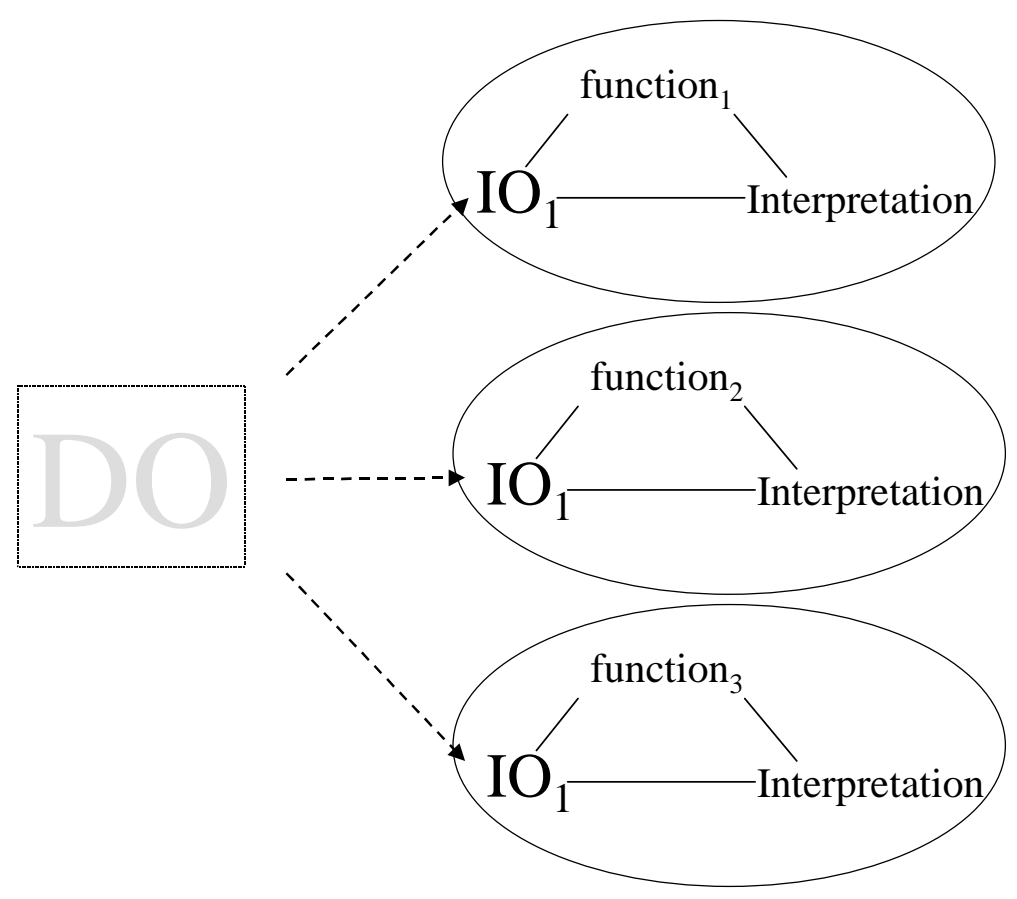

Figure 2: A semiotic understanding of functions, each with their own immediate object (IO) and interpretations, and multifunctionality in relation to the dynamical object (DO). 

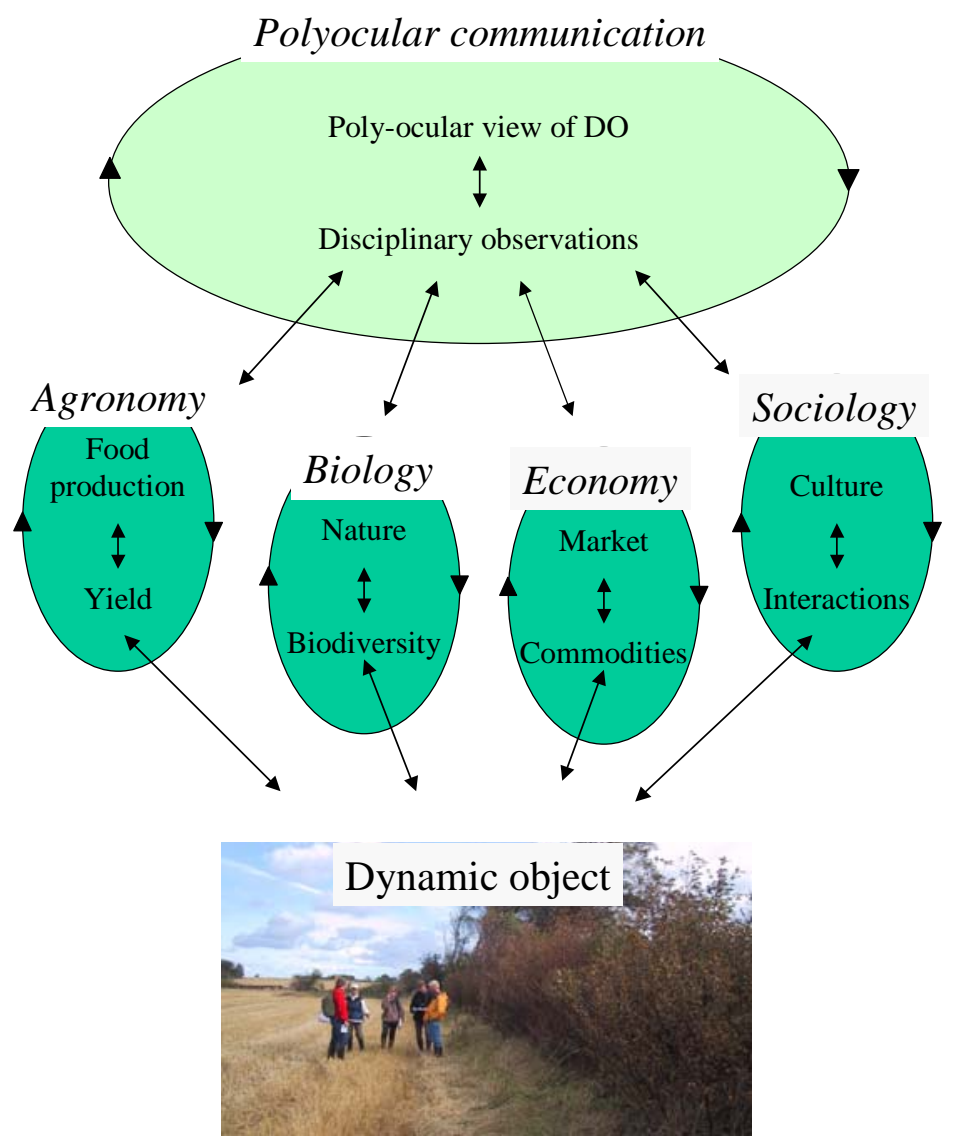

Figure 3: The relationship between disciplines and multidisciplinary communication. 